\title{
Synthesis and Crystal Structures of a mixed-metal Complex with Nitrilotriacetamides
}

\author{
Guichun Sun ${ }^{\mathrm{a}}$, Jingwen Ran ${ }^{\mathrm{b}^{*}}$ \\ 1. Chemical Engineering College, Huanggang Normal University, Huanggang, 438000, China \\ 2. Hubei Key Laboratory for Processing and Application of Catalytic Materials \\ aemail: shenguichun@qq.com, bemail: ranjingwen@hgnu.edu.cn
}

Keywords: crystal structure, nitrilotriacetamide, mixed-metal complex

Abstract. A novel complex with nitrilotriacetamides(L) has been synthesized. Single-crystal X-ray diffraction analysis determined the molecular formula as $\mathrm{C}_{12} \mathrm{H}_{28} \mathrm{~N}_{8} \mathrm{Na}_{2} \mathrm{NiO}_{10}$. The crystal belongs to the triclinic system with $\mathrm{P}-1$ space group. In this molecule, the L ion exhibits an infrequent coordination mode. The nickel center is hexa-coordinated to a slightly distorted octahedral configuration by six nitrogen atoms from two L ligands. The sodium ion is six-coordinated with three oxygen atoms of ligands and three oxygen atoms of water molecules. Two water molecules bridge two $\mathrm{Na}^{+}$ions.

\section{Introduction}

Coordination chemistry of imide-based ligands has been extensively studied owing to the fact that they are usually multi-dentate ligands, thus may bridge metal-ions. On the other hand, their metal complexes have been found to be very important so far, as they have a wide range of applications in technology, medicine and agriculture [1-3]. As a result, a series of tripodal imide-derived ligands have been synthesized and employed in fabricating mononuclear or multi-nuclear metal complexes [4-7]. Among numerous tripodal ligands in this category, nitrilotriacetamide and its derivatives are used as classical N-based ligands due to $\mathrm{N}$-atoms coordinating ability. For example, the tris (2-benzylaminoethyl) amine and tris (4-phenyl-3-aza-2-oxobutyl) amine ligands are famous in forming multi-nuclear metal complexes [8,9] and consequently generate more robust and intricate networks. However, the coordinating ability of O-atoms is ignored. In fact, the introduction of N-donor and O-donor from the nitrilotriacetamide can also coordinate metal ions and generate stable complexes at the same time and result the variation of coordinative mode. Therefore, it is valuable to investigate the coordination chemistry of this ligand. In the paper, we present the synthesis and characterization of the nickel-sodium complex $\left[\mathrm{NiNa}_{2}(\mathrm{~L})_{2}\left(\mathrm{H}_{2} \mathrm{O}\right)_{4}\right]_{\mathrm{n}}$ which is assembled into a 3D supra-molecular network via $\mathrm{H}$-bond interactions.

\section{Experimental}

\section{Materials and physical measurements}

All commercially available chemicals were of analysis reagent grade and used without purification. Ligand L was prepared according to the literature method [10]. Elemental analyses were made on a Perkin-Elmer 240C automatic analyzer. UV-Vis spectra were record on a Beijing general analysis TU-1901 spectrometer. IR spectra were recorded on a FT-IR 170 SX (Nicolet) spectro-photometer in the $4000-400 \mathrm{~cm}-1$ region with $\mathrm{KBr}$ pellets.

\section{Synthesis of complex}

The synthesis of nitrilotriacetamide was carried out according to literature. The title compound was synthesized by adding solid $\mathrm{Ni}\left(\mathrm{NO}_{3}\right)_{2} \cdot 6 \mathrm{H}_{2} \mathrm{O}(290 \mathrm{mg}, 1 \mathrm{mmol})$ to a solution of ligands $(376 \mathrm{mg}, 2$ $\mathrm{mmol})$ and $\mathrm{NaOH}(240 \mathrm{mg}, 6 \mathrm{mmol})$ in ethanol/water $(3: 1,30 \mathrm{ml})$, then the mixture was stirred for $2 \mathrm{~h}$ at room temperature. The solution was filtered and the resulting precipitate was collected and dissolved in a mixture of ethanol and pyridine $(3: 1 \mathrm{v} / \mathrm{v})$ at $50^{\circ} \mathrm{C}$. The solution was allowed to stand in air for $3 \mathrm{~d}$, and blue crystals were formed at the bottom of the vessel on slow evaporation of the solvent 
at room temperature. Yield: 48\%. Anal. Calcd for C12H28N8Na2NiO10: C 26.25, H 5.14, N 20.41. Found: C 26.64, H 5.29, N 20.55.

\section{$\mathrm{X}$-ray data collection and crystal structure determination}

A single crystal with dimensions of $0.35 \mathrm{~mm} \times 0.32 \mathrm{~mm} \times 0.28 \mathrm{~mm}$ was selected for X-ray diffraction. The data were collected at 293(2) K on a Bruker APEXII CCD diffraction analysis using graphite-monochromatic MoK $\alpha$ radiation $(\lambda=0.71073 \AA)$ with a $\omega$ scan mode. A total of 3666 reflections were collected with 2520 unique ones $($ Rint $=0.0126)$. Unit cell dimensions were obtained by full-matrix least-squares refinement. Semi-empirical absorption corrections were applied using the SADABS program [11], the structure was solved by direct methods and refined on F2 by full-matrix least-squares methods using the SHELXL-97 program package [12], and all non-hydrogen atoms were refined with anisotropic displacement parameters. Hydrogen atoms of water were located on a difference Fourier map, while other hydrogen atoms were included in the calculated positions and refined with isotropic thermal parameters riding on the corresponding parent atoms. The final refinement converged at $\mathrm{R}=0.0509$ and $\mathrm{wR}=0.1478\left(\mathrm{w}=1 /\left[\sigma^{2}\left(\mathrm{Fo}^{2}\right)+(0.0929 \mathrm{P})^{2}+0.7251 \mathrm{P}\right]\right.$, where $\left.\mathrm{P}=\left(\mathrm{Fo}^{2}+2 \mathrm{Fc}^{2}\right) / 3\right)$. The largest difference peak and hole are 0.901 and $-0.869 \mathrm{e} / \AA^{3}$, respectively and $\mathrm{S}=1.07$.

\section{Results and discussion}

\section{Structural description}

The complex crystallizes in the triclinic system with space group P-1. Molecular structure and labeling scheme for $\left[\mathrm{NiNa}_{2}(\mathrm{~L})_{2}\left(\mathrm{H}_{2} \mathrm{O}\right)_{4}\right]_{\mathrm{n}}$ are shown in Fig. 1. In the structural unit of the molecule, there are two ligands anions and four coordinated water molecules. Selected bond lengths and bond angles for the title complex are given in Table 1 .
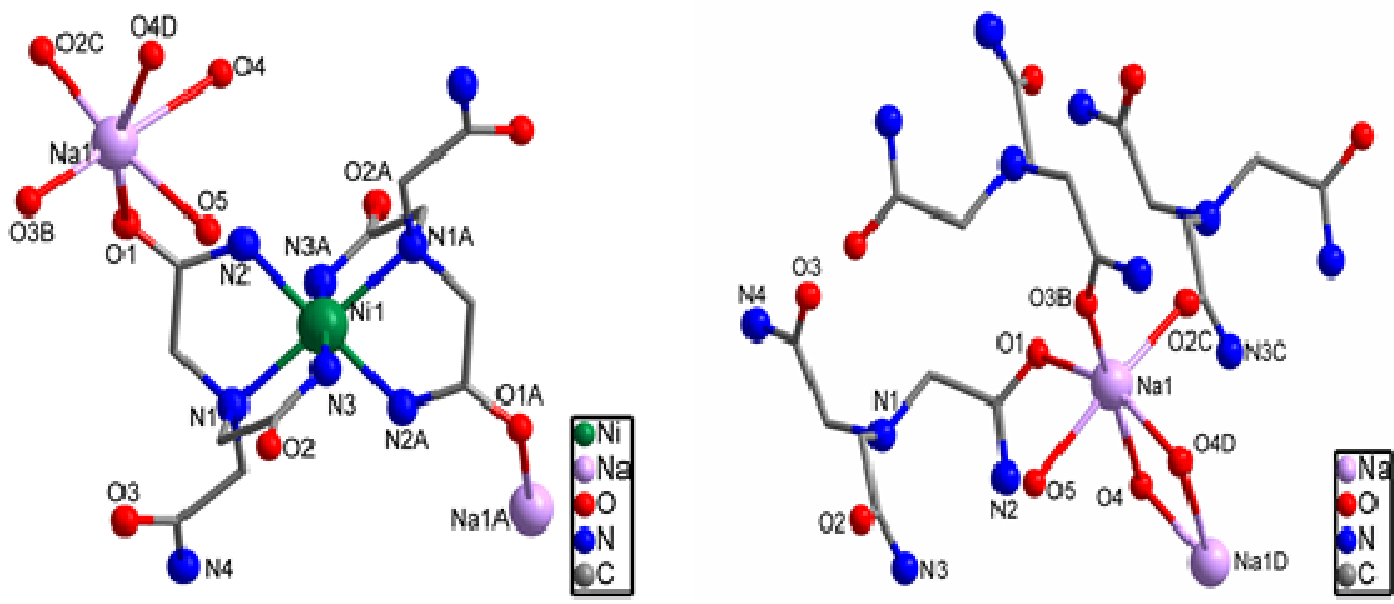

Fig. 1 Coordination environment around the $\mathrm{Ni}$ (II) and $\mathrm{Na}$ (I) ion in the complex at $30 \%$ probability thermal ellipsoids

The centre nickel cation is hexa-coordinated to six $\mathrm{N}$ atoms from two nitrilotriacetamides and forms a slightly distorted octahedral configuration which is centrosymmetric as $\mathrm{Ni}$ (II) occupies an inversion center. The $\mathrm{Ni}$ atom is coordinated in a planar geometry by the $\mathrm{N}$ atoms of imides. Two trans axial sites of this coordination environment are occupied by $\mathrm{N}$ atoms of tertiaryamines. In the equatorial plane the $\mathrm{Ni}-\mathrm{N}$ distance is 2.049(2) $\AA$ for $\mathrm{Ni}(1)-\mathrm{N}(2)$ and 2.022(2) $\AA$ for $\mathrm{Ni}(1)-\mathrm{N}(3)$, The axial Ni-N bond is appreciably extended which is $2.136(2) \AA$ for $\mathrm{Ni}(1)-\mathrm{N}(1)$. The angles formed by the nickel ion and two adjacent coordination $\mathrm{N}$ atoms are close to 90 , with a deviation of 1.28. Two diagonally coordinated $\mathrm{N}$ atoms and the central nickel are co-linear. Each sodium cation is coordinated by three oxygen atoms from three acyl groups and three water molecules, with the $\mathrm{Na}-\mathrm{O}$ bonds falling in the range of 2.283(3)-2.568(3) $\AA$ (average 2.443 $\AA$ ), longer than Ni(1)-N. So each sodium cation is in octahedron geometry. Two adjacent $\mathrm{O}(4)$ from water molecules bridge two sodium cations from different unit. As 
the $\mathrm{Na}-\mathrm{O}(4)$ bonds, the complex forms a 3D unit structure, the complex is best described as [NiNa2 (L) 2(H2O) 4] n, which represents the repeating unit of the 3D structure.

Table 1. Selected Bond Lengths $(\AA)$ and Bond Angles $\left(^{\circ}\right)$

\begin{tabular}{|c|c|c|c|c|c|}
\hline Bond & Dist. & Bond & Dist. & Bond & Dist. \\
\hline $\mathrm{Ni}(1)-\mathrm{N}(3)$ & $2.022(2)$ & $\mathrm{Ni}(1)-\mathrm{N}(2)$ & $2.049(2)$ & $\mathrm{Ni}(1)-\mathrm{N}(1)$ & $2.136(2)$ \\
\hline $\mathrm{Na}(1)-\mathrm{O}(3) \# 2$ & $2.283(3)$ & $\mathrm{Na}(1)-\mathrm{O}(2) \# 3$ & $2.335(3)$ & $\mathrm{Na}(1)-\mathrm{O}(5)$ & $2.385(3)$ \\
\hline $\mathrm{Na}(1)-\mathrm{O}(4) \# 4$ & $2.390(3)$ & $\mathrm{Na}(1)-\mathrm{O}(1)$ & $2.568(3)$ & $\mathrm{Na}(1)-\mathrm{O}(4)$ & $2.689(3)$ \\
\hline Angle & $\left({ }^{\circ}\right)$ & Angle & $\left({ }^{\circ}\right)$ & Angle & $\left({ }^{\circ}\right)$ \\
\hline $\mathrm{N}(3) \# 1-\mathrm{Ni}(1)-\mathrm{N}(3)$ & 180.0 & $\mathrm{~N}(3) \# 1-\mathrm{Ni}(1)-\mathrm{N}(2) \# 1$ & $91.28(11)$ & $\mathrm{N}(3)-\mathrm{Ni}(1)-\mathrm{N}(2) \# 1$ & $88.72(11)$ \\
\hline $\mathrm{N}(3) \# 1-\mathrm{Ni}(1)-\mathrm{N}(2)$ & $88.72(11)$ & $\mathrm{N}(3)-\mathrm{Ni}(1)-\mathrm{N}(2)$ & $91.28(11)$ & $\mathrm{N}(2) \# 1-\mathrm{Ni}(1)-\mathrm{N}(2)$ & $180.00(1)$ \\
\hline $\mathrm{N}(3) \# 1-\mathrm{Ni}(1)-\mathrm{N}(1) \# 1$ & $82.83(9)$ & $\mathrm{N}(3)-\mathrm{Ni}(1)-\mathrm{N}(1) \# 1$ & $97.17(9)$ & $\mathrm{N}(2) \# 1-\mathrm{Ni}(1)-\mathrm{N}(1) \# 1$ & $80.74(9)$ \\
\hline $\mathrm{N}(2)-\mathrm{Ni}(1)-\mathrm{N}(1) \# 1$ & $99.26(9)$ & $\mathrm{N}(3) \# 1-\mathrm{Ni}(1)-\mathrm{N}(1)$ & $97.17(9)$ & $\mathrm{N}(3)-\mathrm{Ni}(1)-\mathrm{N}(1)$ & $82.83(9)$ \\
\hline $\mathrm{N}(2) \# 1-\mathrm{Ni}(1)-\mathrm{N}(1)$ & $99.26(9)$ & $\mathrm{N}(2)-\mathrm{Ni}(1)-\mathrm{N}(1)$ & $80.74(9)$ & $\mathrm{N}(1) \# 1-\mathrm{Ni}(1)-\mathrm{N}(1)$ & $180.00(1)$ \\
\hline $\begin{array}{l}\mathrm{O}(3) \# 2-\mathrm{Na}(1)-\mathrm{O}(2) \# \\
3\end{array}$ & $98.38(1)$ & $\mathrm{O}(3) \# 2-\mathrm{Na}(1)-\mathrm{O}(5)$ & $94.68(11)$ & $\mathrm{O}(2) \# 3-\mathrm{Na}(1)-\mathrm{O}(5)$ & $166.34(1)$ \\
\hline $\begin{array}{l}\mathrm{O}(3) \# 2-\mathrm{Na}(1)-\mathrm{O}(4) \# \\
4\end{array}$ & $91.45(11)$ & $\begin{array}{l}\mathrm{O}(2) \# 3-\mathrm{Na}(1)-\mathrm{O}(4) \# \\
4\end{array}$ & $99.64(1)$ & $\mathrm{O}(5)-\mathrm{Na}(1)-\mathrm{O}(4) \# 4$ & $83.99(10)$ \\
\hline
\end{tabular}

Symmetry transformation: $\# 1-\mathrm{x}+2,-\mathrm{y}+1,-\mathrm{z} \quad \# 2-\mathrm{x}+2,-\mathrm{y}+1,-\mathrm{z}+1 \quad \# 3 \mathrm{x}, \mathrm{y}+1, \mathrm{z} \quad \# 4-\mathrm{x}+3,-\mathrm{y}+2,-\mathrm{z}$ $\# 5 \mathrm{x}, \mathrm{y}-1, \mathrm{z}$

Each sodium cation is coordinated by three oxygen atoms from three acyl groups and three water molecules, with the $\mathrm{Na}-\mathrm{O}$ bonds falling in the range of 2.283(3)-2.568(3) $\AA$ (average 2.443 $\AA$ ), longer than Ni(1)-N. So each sodium cation is in octahedron geometry. Two adjacent $\mathrm{O}$ (4) from water molecules bridge two sodium cations from different unit. As the $\mathrm{Na}-\mathrm{O}$ (4) bonds, the complex forms a $3 \mathrm{D}$ unit structure, the complex is best described as [NiNa2 (L) 2(H2O) 4] n, which represents the repeating unit of the $3 \mathrm{D}$ structure. 


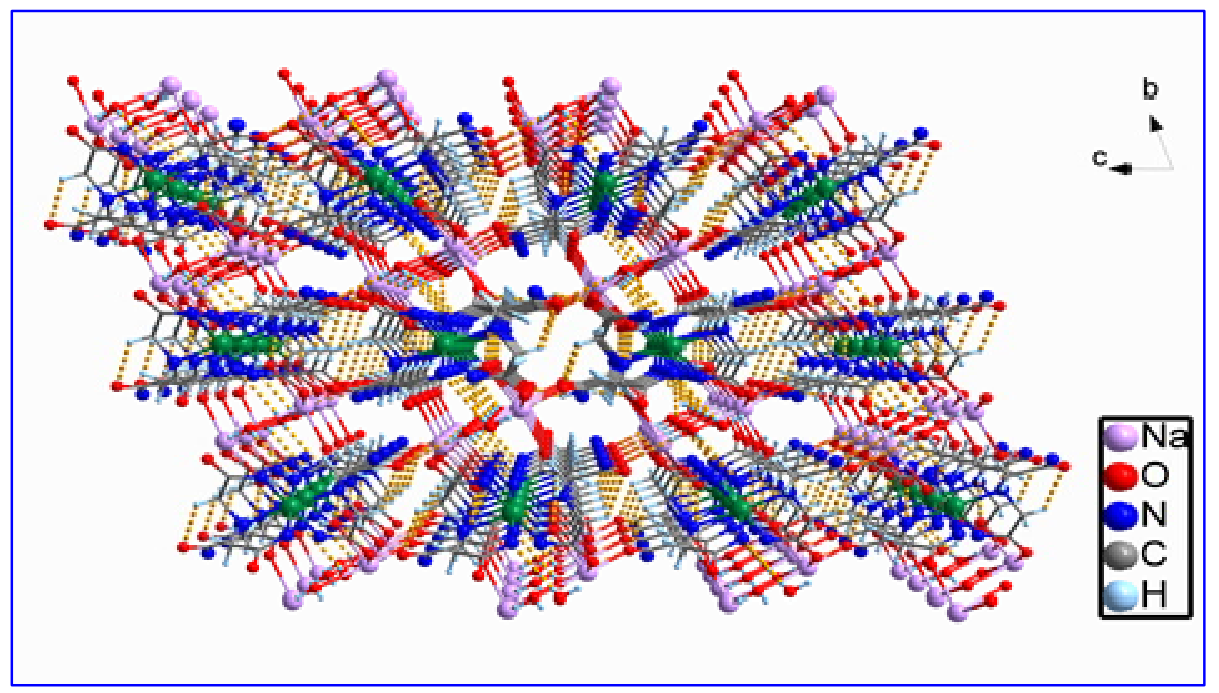

Fig. 2 Packing diagram of $\left[\mathrm{NiNa}_{2}(\mathrm{~L})_{2}\left(\mathrm{H}_{2} \mathrm{O}\right)_{4}\right]_{\mathrm{n}}$ in the crystal viewed along the a-axis

\section{Spectrum analysis of the complex}

The UV/Vis spectra of complex in methanol shows a wide peak at $292 \mathrm{~nm}$. The peak should be ascribed to the $n \rightarrow \pi *$ orbital transition for imide group. IR spectrum of the complex shows strong absorption peaks at $1631.7 \mathrm{~cm}-1$, which is assigned to the $\mathrm{v} \mathrm{C}=\mathrm{O}$ absorption of imide group. A band at $3531 \mathrm{~cm}-1$ could be assigned to the stretching vibration $(\mathrm{vOH})$ of coordinated water molecules, and the broad shape of this band suggests the existence of $\mathrm{H}$-bonds. The weak bands of $v \mathrm{~N}-\mathrm{H}$ are observed at $3420 \mathrm{~cm}-1$ for and $3321 \mathrm{~cm}-1$. The bonds at 2927.7 and $1452.3 \mathrm{~cm}-1$ are assigned to the stretching vibrations and out-of-plane bending of $\mathrm{C}-\mathrm{H}$ bond for methylene.

\section{Conclusion}

A novel nickel coordination complex with nitrilotriacetamides was prepared and characterized in this paper. The molecule unit is consisted by a central Ni (II), two $\mathrm{Na}+$, two nitrilotriacetamides ligands and four coordinated water molecules. Central $\mathrm{Ni}$ (II) is coordinated to a slightly distorted octahedron by two nitrilotriacetamides. $\mathrm{Na}+$ is coordinated by oxygen atoms from imides group and water. The UV-Vis and IR spectrum show the different groups.

\section{Acknowledgements}

This research was supported by the Educational Department of Hubei Fund(grant No. D20152902).

\section{Reference}

(1) Saroja J.; Manivannan V.; Chakraborty P.; Pal S. A diiron(III) complex containing N-N bridges. Synthesis, structure, and properties. Inorg. Chem. 2013, 34, 3099-3101.

(2) Mo H.; Guo D.; Duan C.Y.; Li Y.T.; Meng Q. A three-dimensional porous metal-organic framework $\left[\mathrm{Fe}_{2} \mathrm{~L}_{3}\right.$ (DMF) $\left.{ }_{7}\left(\mathrm{C}_{4} \mathrm{H}_{10} \mathrm{O}\right){ }_{0.5}\right]$ constructed from triple-helices $\{\mathrm{L}=$ bis $[2$, 4-dihydroxybenzaldehyde] hydrazone $\}$. Dalton Trans. 2012, 2, 3422-3424.

(3) Ruben B.; Klaus H.; Aviva L.; Peter A. L... Synthesis and Characterization of a Chromium (V) cis-1,2-Cyclohexanediolato Complex: A Model of Reactive Intermediates in Chromium-Induced Cancers. Inorg. Chem. 2012, 51, 11238-11240.

(4) Zeng H. F.; Li T. H.; Yan Z. W.; Luo S. J.; Li F. Two Porous Metal-Organic Frameworks Showing Different Behaviors to Sodium Cation. Crystal Growth and Design, 2010, 10, 475-478.

(5) Kang D. Y.; Lee J. E.; Lee S. Y.; Choi K. S.; Lee S. S. Four-, six- and eight-coordinated lead(II) complexes with amine- or amide-type tripodal ligands. Inorg. Chem.Commun. 2007, 10, 1105-1108. 
(6) Youhei S.; Takefumi H.; Takeshi F.; Hiroaki H.; Naohide M.; Nazzareno Re B.; Jerzy M.; Yuichi I.; Asako I. K.; Takumi K. A linear CuII-GdIII-CuII-GdIII complex derived from the assembly reaction of [NaCuIIH3Ldpen(meso)] [GdIII(thd)3(H2O)2](H3L= meso-1,2-diphenyl-1-(2-oxybenzamido)-2-(2-oxy-3-ethoxybenzylideneamino)ethane and Hthd = 2,2,6,6-tetra-methyl-3,5-heptanedione). Polyhedron, 2011, 30, 1127-1133.

(7) Li C.J.; Feng Z. J.; Dou J. M.; Li D. C.; Wang D. Q. Synthesis and supramolecular structure of Zn, Cd, Hg complexes constructed by 2,3-naphtho-15-crown-5. J. Mol. Struct., 2010, 970, 19-26.

(8) Katerina N. L.; Athanassios K. B.; Vassilis P.; Catherine P. R. Copper(II)-mediated oxime-nitrile coupling in non-aqueous solutions: Synthetic, structural and magnetic studies of the copper(II)-salicylaldehyde oxime reaction system. Inorg. Chim. Acta. 2011, 370, 50-58.

(9) Ran J. W.; Zhang S. Y.; Xu B.; Xia Y. Z.; Guo D.; Zhang J. Y. Tetranuclear nickel(II) complex with tripodal hydroxyl ligand functionalized by additional salicylaldehyde donor pendant: Synthesis, crystal structure and magnetic property. Inorg. Chem. Commun., 2013, 11, 73-76.

(10) Donald H. T.; Williamsville; George C. H.; Clarence N. Y. Process for the preparation of nitrilotriacetamides. US patent, 1974, Ser. No. 103277.

(11) Sheldrick, G. M. SHELXS-97, Program for Crystal Structure Solution. University of Göttingen, Germany 1990.

(12) Sheldrick, G. M. SHELXL-97, Program for Crystal Structure Refinement. University of Göttingen, Germany 1997. 